\title{
Correction to: Aggregated Results of Access Programs Implemented by Universities in Chile: Students' Persistence using a Matched Sample
}

\author{
Maria Veronica Santelices ${ }^{1} \cdot$ Catherine Horn $^{2} \cdot$ Ximena Catalán $^{1}$. \\ Alejandra Venegas ${ }^{3}$
}

Published online: 10 March 2021

(c) International Association of Universities 2021

\section{Correction to: Higher Education Policy (2021) https://doi.org/10.1057/s41307-021-00223-3}

The author Alejandra Venegas (independent researcher) is located at Santiago, Chile

The footnote in Table 1 should read: Family income dummy variable: proportion of students with monthly family income below USD \$1100.

Standardized GPA 1 : Should read: Standardized GPA $\left(\right.$ Std_GPA $\left._{1}\right)$ : Student's grade point average during first year of college (standardized by institution).

The original article has been corrected.

Publisher's Note Springer Nature remains neutral with regard to jurisdictional claims in published maps and institutional affiliations.

The original article can be found online at https://doi.org/10.1057/s41307-021-00223-3.

Maria Veronica Santelices

vsanteli@uc.cl

1 Facultad de Educación, Pontificia Universidad Catolica de Chile, Vicuña Mackenna 4860, Macul, Santiago, Chile

2 University of Houston, Houston, USA

3 Santiago, Chile 